\title{
Thematic Analysis of the Children's Drawings on Museum Visit: Adaptation of the Kuhn's Method
}

\author{
Tamara Kisovar-Ivanda ${ }^{1, *}$ \\ ${ }^{1}$ Department of Teacher and Pre-school Teacher Education, University of Zadar, Zadar, Croatia \\ *Correspondence: Department of Teacher and Pre-school Teacher Education, University of Zadar, Zadar, Croatia. \\ E-mail: tivanda@unizd.hr
}

Received: January 27, 2014

Accepted: May 24, 2014

Online Published: June 10, 2014

doi:10.5430/wje.v4n3p60

URL: http://dx.doi.org/10.5430/wje.v4n3p60

\begin{abstract}
Researchers are using techniques that allow children to express their perspectives. In 2003, Kuhn developed the method of data collection and analysis which combined thematic drawing and focused, episodic interview. In this article the Kuhn's method is adjusted using the draw and write technique as a research methodology. Reflections on the technique are drawn from our experience of using it in study with primary school students aged 8 to 10 years. This was part of a larger study undertaken to investigate the relationship between the way younger school-age students perceive the museum and degree of didactic structuring of museum contents. The students are asked to draw a picture showing their museum visit to Museum of Ancient Glass in Zadar and to write a shot text about it. Free written expression of students and their drawings illustrate children's abilities to convey their opinions when there is an enabling climate created. Analysis of children's' drawings has provided insight into the structure of students' perceptions, its orientation and content. At the same time it provided us with the information about the process of perceiving museum exhibits and museum environment by the students who were involved in the pre-visiting curricular activities and those who were not involved in them, as well as the information on students' perception of social interaction and abstract values that can be seen in the drawings.
\end{abstract}

Keywords: analysis of children's drawings; draw and write technique; students perceptions of the museum

\section{Introduction}

\subsection{Children's Drawings}

Drawing is a natural play activity for children and it comes naturally to most children. Childhood artworks interpret their lived experiences and we engage with their drawings as metaphorical representations of sensory experience of the world. Malchiodi (1998) reports on growing fascination over the past century with the emotional and psychological aspects of children's art expressions, particularly from the fields of psychology, psychiatry, and art therapy. In her report drawing is recognized as one of the most important ways that children express themselves and has been repeatedly linked to the expression of personality and emotions.

Exactly in recent years there has been a shift from a de-contextualized, psychological focus on children's drawings towards the increased interest in children's meaning making through drawing, and a focus on the socio-cultural contexts of drawing activity (Anning, 2003; Louis, 2005). School and play are areas of common expression in childhood. Considering this issue from the perspective of a teacher, Hawkings (2002) recognizes drawing as a form of visual language. Young children experiment with that form of visual language, often reflecting an instinctive psychological engagement with the process. At the same time, older children recognize the potential of drawing as a means of communication and representing the visual world. However, children's drawings cannot be easily understood out of context. Louis (2005, p. 353) concludes that young children undoubtedly draw upon cultural conventions, social situations, and denotative systems to give shape and form to their experience. Artistic growth is a non-linear process in which children access multiple pictorial systems and explore a variety of pictorial repertoires to construct meaning through connections across symbol systems. 
Although the content, which is included or excluded from a drawing, may have as much to do with children's ability to graphically represent certain things as it has with the ideas they want to convey, researchers are aware of influences from mainstream culture and remaining alert to influences from personal cultures nested within it. So they are using techniques that allow children to express their perspectives. In this article, the issues for the child and researcher of using the draw and write technique as a research methodology are explored.

\subsection{Psycho-diagnostic Use of Children's Drawings}

In the late 1800s and early 1900s many researchers noted that drawings could be used as measures of intelligence and personality (Buggle, 2002, Malchiodi, 1998). Piaget used drawings to study children's conception of space, Freud and Jung, had interests in the interconnections among art, symbols, and personality. Malchiodi (1998), art therapist and artist, described the basic principles of creative therapy, by which the creative process can help an individual to express problems, raising awareness of emotions and conflict resolution. Creative therapy is based on the idea that the characteristics of individuals are reflected in their work, and that the creative process of art can be a means of expression and therapeutic communication. The same author states that the therapeutic work with children is especially complex because a child's drawing is multidimensional, considering that it reflect the child's personal experience and feelings, its level of development, socio-cultural influences and context in which children create.

Psychiatrists further use children's drawings for therapeutic purposes. Interpreting the results of Tardieu's (1872), Simon (1876) and Lombroso (1895), Malchiodi (1998, p. 27), emphasizes that most writers of this time period believed that the art expressions of mentally ill patients confirmed their diagnoses, particularly schizophrenia. Artworks of patients drew attention to the notion that art expressions might have both diagnostic value as well as play an important role in rehabilitation (MacGregor, 1989). Attention to children's drawings came out of the growing interest at the turn of the century. It paralleled both the attraction to art created by mental patients and the development of child psychology at that time. Initial studies of children's art expression centered around observing what children drew and how they drew at different ages. Malchiodi (1998) mentions Goodenough's Draw-A-Man (DAM) test (1926) and points out the significance of influence of Machover's (1949) Draw-A-Person projective test on almost all research on clinical applications of human figure drawings. Koppitz (1968, in Malchiodi, 1998) constructed developmental scoring systems for children's drawings, observing a human figure a child draws as a reflection of the child's inner representation of self. Pediatrician Donald Winnicott (1971) explored the idea that children's art could be used as a means of communication between therapist and child. He developed a technique in which the child and therapist create a scribble through drawing together. According to Silver and Ellison (1995), in process of identifying and assessing self-images in drawings by delinquent adolescents, children's drawings are images that can reflect their thinking and forms can represent an idea but further investigation would be worthwhile. The majority of investigations that has been presented focused largely on projective drawing tasks or tests and the symbolic meanings of images. The fundamental tenets of art therapy involve communication, control, and resolution of emotional conflicts through art making (Wittmann, 2010, Porter, 2011, De Zan, 2013). These concepts are closely related to psychodynamic theories that emphasize the connection between unresolved feelings and emotional adjustment.

\subsection{Children's Drawings Analysis in the Educational Context}

In the educational context, drawings have been used as assessment tools but reports of using children's drawings as an evaluation tool are relatively rare. Carini (1982) collected children's artwork over a five year period as part of an evaluation of the New York State Experimental Pre- kindergarten Program. Carini's analysis focused on these materials as a way to gain access to the child's personal statements of meaning (1982, p. 6). Relatively few studies have focused on children's art as an expression of cultural context. In that context children's drawings were used as a way of better understanding how children make sense of the political, moral, and spiritual world (Coles, 1986), in order to understand the way that culture mediates children's reactions to specific health care situations (Fassler, 1986), or as a way to investigate the relationship between culture acquisition and cultural identity in the West Indies (Gamradt, Staples \& Curry, 1991).

Wilson and Wilson (1987) propose that graphic representation should be understood as a symbolic language. They emphasize that symbolic languages (verbal, mathematical, or graphic) are culturally determined and they are a product of culture-specific experiences. The complexity of the graphic language system is therefore, according to Wilson and Wilson, shaped by cultural context. Their analytical strategies examine children's drawings for both aesthetic and thematic content.

In recent pedagogical papers children's drawings are used in explaining certain dimensions of teaching methodology, directed towards understanding the pedagogical questions about the validity of process of teaching 
children how to draw (Anning \& Ring, 2004) children's aesthetic representations are used to understand their reading comprehension (Cuero, 2008), and they also find their application in the pedagogical evaluation of social aspects in formal and informal learning (Magolda, 2007, Locke \& Riley, 2009).

Drawings have the ability to reflect children's unique perceptions and experiences with others as well as the influences of others. It is important to remember that drawings are not made in isolation from the world. Teachers, parents, school peers, museum curators and their activities do affect the content of children's expressive work, and these educational aspects are often included in their drawings. In our study, there was interest in locating empirical work employing children's drawings as a way to obtain additional information, in order to gain insight into the problem of children's perception of “ museum world” and a way they learn about it.

\subsection{Kuhn's Qualitative Analysis and Interpretation of Children's Drawings}

The Kuhn's model of analysis of children's drawings (Khun, 2003) was originally used in kinesiology for the evaluation of children's attitudes about the game and sports activities in the school area and has been implemented in research conducted in Germany. The Kuhn's method is adjusted using the draw and write technique as a research methodology (Horstman, Aldiss, Richardson, \& Gibson, 2008; Reeve, \& Bell, 2009). According to Kuhn (2003), the main problems of qualitative analysis and interpretation of children's drawings can be seen within the four main groups of features of children's drawings (Kuhn, 2003): (1) distinguish the level of drawing talent, (2) conditioning of drawings by social and environmental conditions, (3) difficulties in interpretation due to disuse of the psychological interpretation, and (4) the uncertainty of the meaning of drawing.

1) Children differ according to the level of drawing talent, so the qualitative analysis of children's drawings does not strive for assessing children's iconographic expression.

2) The content of drawings depends on current social and environmental conditions in which the child lives.

3) Adult evaluators may have difficulties in interpreting children's drawings without using the criteria of psychological interpretation. However, during the qualitative analysis of children's drawings, the interpretation of the content elements of the drawing, according to the previously agreed criteria, is made. Evaluators focus on the description of the objective elements of drawings, which gives them possibility to interpret the latent structure (for example, a preferred activity).

4) The drawings contain the visible elements, while "meaning” remains to some extent uncertain.

Although aware of these difficulties, Kuhn (2003) does not advise to create too narrow and restrictive interpretation of iconographic categories of data. Instead of defining narrow and rigid categories, he proposes model based on the observation: motives, the text in the drawing, the human way of portraying the characters, their movements and activities and interactions with each other. At the beginning of Kuhn's analysis, the elements (objects, persons) and structural categories (people's actions) are observed. The first step of analysis includes the analysis of qualitative categories, which are quantified below. The focus, however, is not on quantification but on describing the essential elements of interpretation and interpretation is carried out in three steps: (1) initial descriptive step of evaluation, (2) evaluation of space or location, social relationships and activities, and (3) thematic evaluation of drawings.

1) Initial, descriptive step of evaluation tends to identify drawing elements distinguishing between persons (for example, child, teacher), the environment (for example, grass, sun, animals), objects (for example, table football, shelf), text (title, label, words in a balloon, etc.). Use of this identification allows us to spot types of communications at the descriptive level: communication presented by drawings and text, only the drawing, just text.

2) The second interpretative step is the evaluation of space or location, social relationships and activities.

3) The third interpretative step directs our attention to the thematic evaluation of drawings.

In addition to the five steps of interpretation Kuhn distinguishes five thematic levels: (1) static display of a person or object, (2) the action, (3) display of a special occasional event, (4) representation of the actual items that could serve as an expression of admiration or children's fantasies about him and (5) display of some abstract values which the child is prone to.

It is important to note that the Kuhn's model of interpretation of children's drawings was intended for the evaluation of children's attitudes about the game and sports activities in the school area, but the structure and the analytical approach of this model are applicable to the interpretation of children's drawings focused on the display of the various dimensions of museum communication. 


\section{Method}

\subsection{Adjustment of the Khun's Model}

For the purposes of this study, Kuhn's model is adapted to the analysis and interpretation of children's drawings in the context of museum communication specifying the following steps:

1) Identification of the drawing elements in which we can see the difference:

a) people (students, teacher, researcher, museum staff)

b) space (museum environment, museum interior, shelves)

c) objects (exhibits, other noted items)

d) text (title, labels, words, or phrases in balloons)

e) symbolic elements (heart, question mark, exclamation mark, arrow).

Identification of the drawing elements includes determining of the shape of the descriptive presentation of museum communication:

a) drawing and text display

b) display of drawing only

c) display of text only.

2) Explaining of interpretative meaning of space or location, social relationships and activities.

3) Thematic interpretation of drawings includes five levels:

a) static display of persons (students, teacher, researcher, museum employee) or objects (museum exhibits, photos, shelf or showroom floor)

b) view of the activity (in the museum or another area that is in any way connected with the museum communication)

c) the presentation of a specific event associated with the museum communication

d) display of museum objects that child likes and which observes and displays in a drawing in a real situation or a situation from imagination

e) display of some abstract values which the child tends (for example, the beauty of a museum installation, the emotionality in communication, love and friendship, appetence toward peers or adults, etc.).

Described steps were used as the basis for the designing of protocol for the analysis and interpretation of children's drawings, which was used in the analysis of the research results.

\subsection{Research Results}

Reflections on the technique are drawn from our experience of using it in study with primary school students aged 8 to 10 years. This was part of a larger study (431 research participants from primary schools in Zadar, Benkovac and Privlaka in Croatia) undertaken to investigate the relationship between the way younger school-age students perceive the museum and degree of didactic structuring of museum contents.

Since the pedagogical experiment was used in the study, students of the experimental group were involved in the pre-visiting didactically structured activities at school while students from the control group had no preparatory activities prior to the museum visit. Using Likert scales in the survey enabled us to quantitative or numerical description of the research problem. Open questions in the survey enabled us to collect free written expression of students and their drawings. Semi-structured interviews with teachers were also conducted. In the combined study (Cohen, Manion, Morrison, 2006.) quantitative and qualitative approaches were combined to connect paradigmatic systems and take advantage of both paradigms.

Sampling, with respect to the place of residence and students' school attendance, was done according to the number of residents, which was proportionately with the development of museum activities. The number of respondents in each site was proportional to the number of inhabitants. The following categories were used in the research: major city (Zadar), small town (Benkovac) and a smaller place (Privlaka).

Within the framework of research, the students were asked to draw a picture showing their museum visit to Museum of Ancient Glass in Zadar and to write a shot text about it. Free written expression of students and their drawings 
illustrate children's abilities to convey their opinions when there is an enabling climate created. After the process of analysis of students' drawings as described in the previous section, it could be concluded that the group of students from Zadar is perceptually more focused on museum exhibits than on the significance of the fact that they visited the museum institution (image of indoor and outdoor space of the museum). Since Zadar has developed a network of museums, only the fact of visiting museum is not a priority in relation to other dimensions of students' perceptions. But it is noticeable that more students from Benkovac and Privlaka (places without a developed museum network) focus on indoor and outdoor space of museum, thus emphasizing the subjectively perceived importance of their own experience of the museum visit itself.

A technique of analyzing children's drawings enabled us to identify museum artifacts which the students of the experimental group met during their pre-visiting activities and that influenced the content and direction of their perceptions. Figure 1 presents drawings made by students included in experimental group. These drawings contain detailed and precisely presented exhibits, with defining of their spatial positioning in the museum space, in contrast to simpler presentations of exhibits and their spatial positioning on drawings of students in the control group (Figure 2).
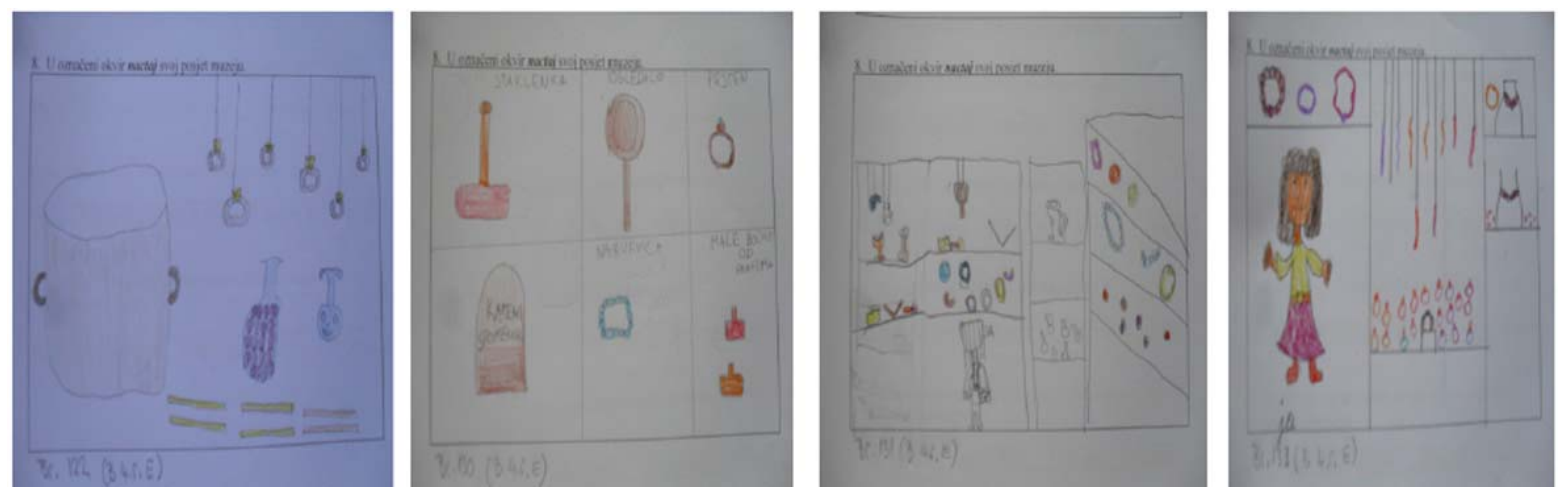

Figure 1. Drawings of the Students in the Experimental Group - Focus on Objects
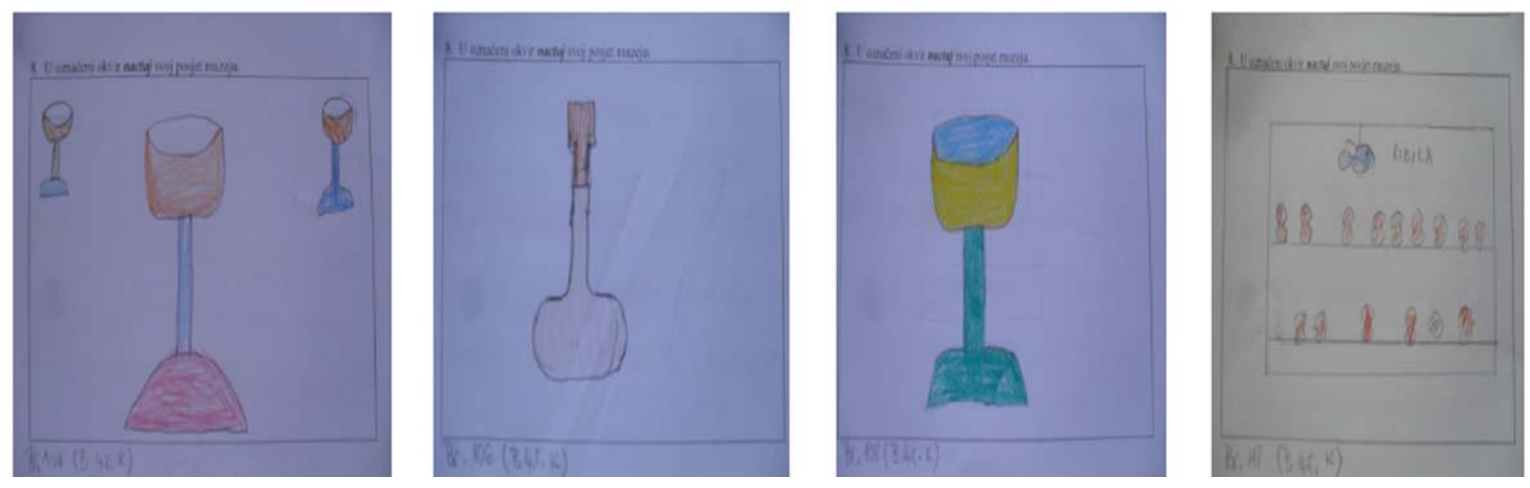

Figure 2. Drawings of the Students in the Control Group-Focus on Objects

The same technique of analyzing children's drawings enabled us also to identify some abstract values expressed on them. Drawings made by students of the control group content to a greater extent the expressions of friendship, fellowship, liking as well as admiration and respect (Figure 4). Figure 3 presents drawings made by students from the experimental group. In these pictures it is possible to notice a wider range of abstract values, with particular emphasis on the amazement with exhibits, friendship, respect, and satisfaction with the museum activities added to previously mentioned abstract values among students in the control group. 


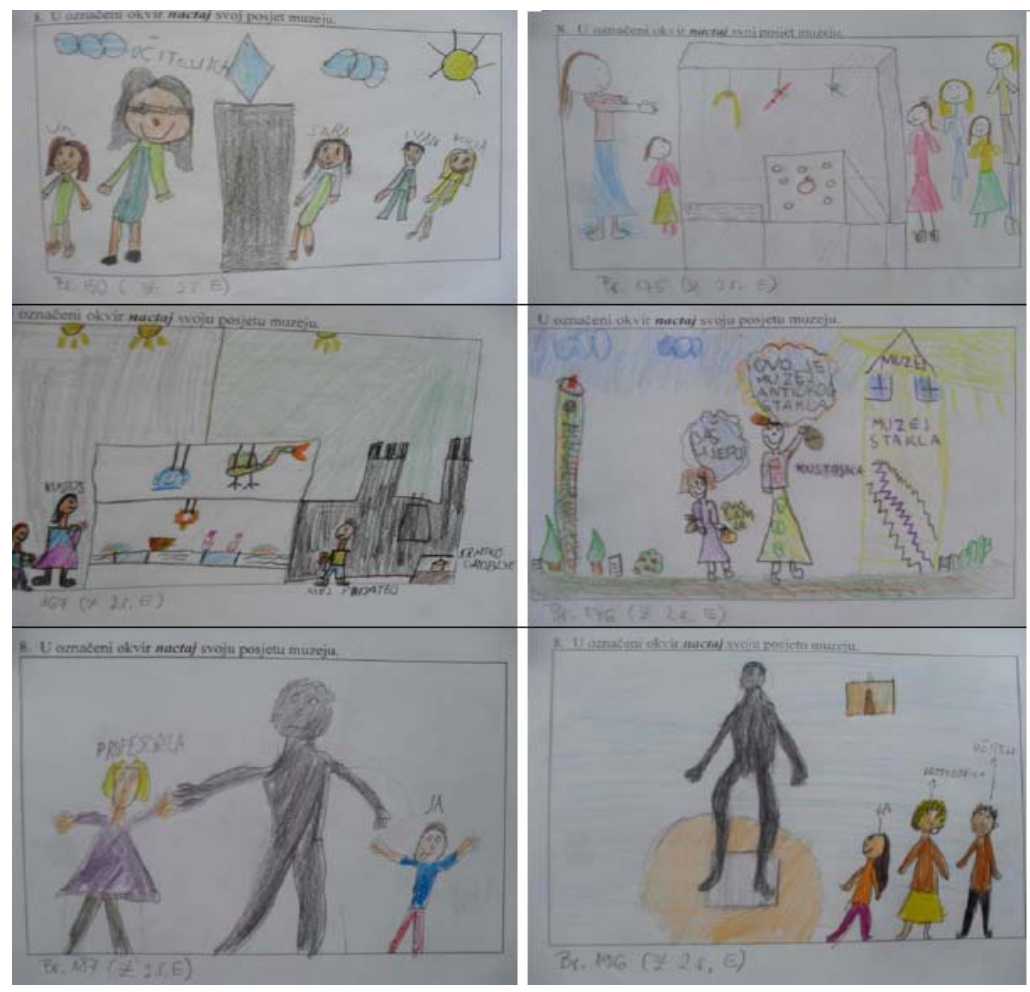

Figure 3. Drawings Made by Students of the Experimental Group - Social Interactions
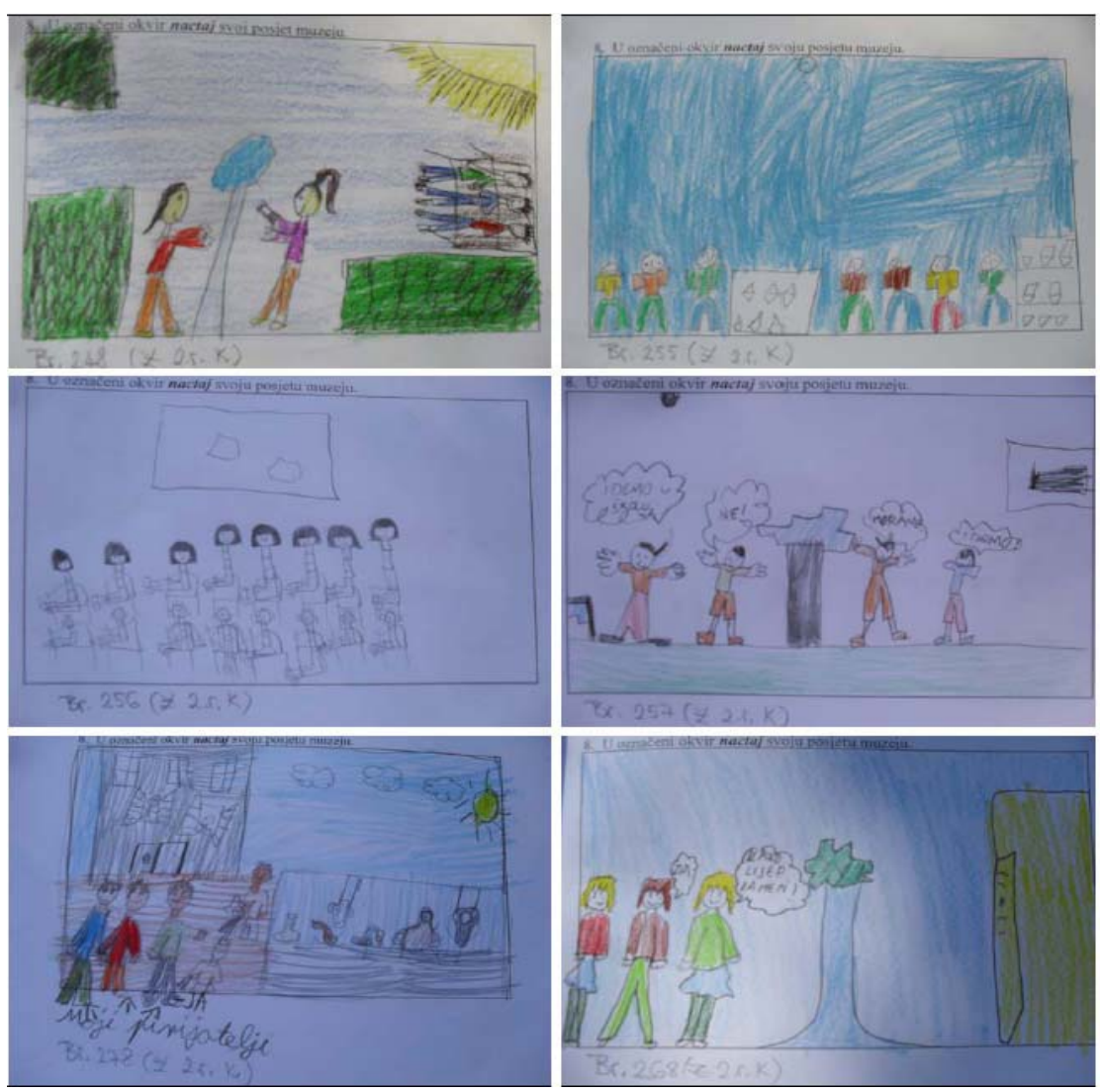

Figure 4. Drawings Made by Students of the Control Group - Social Interactions 
Described technique of analyzing children's drawings enabled us to identify social interactions within peer communication, as well as social interactions between children and adult persons in museum environment. Drawings made by students of the experimental group contain much more views of communication with curators and teachers, added to drawn presentations of interactions among peers. At the same time, the social interaction of children and adults are visible on much fewer drawings made by students in the control group, with emphasized share of presentations of peer communication on their drawings.

\section{Conclusions}

The Kuhn's model of analysis of children's' drawings was originally used in kinesiology for the evaluation of children's attitudes about the game and sports activities in the school area. Its adjustment on thematic analysis of the students' perceptions of museum, in context of educational research directed towards efficient modeling of the school curriculum, enabled us to enrich the image of students' perceptions of the museum. Analysis of children's drawings has provided insight into the structure of students' perceptions, its orientation and content. At the same time it provided us with the information about the process of perceiving museum exhibits and museum environment by the students who were involved in the pre-visiting curricular activities and those who were not involved in them, as well as the information on students' perception of social interaction and abstract values that can be seen in the drawings. Such data allow school and museum professionals richer and more complex insight into the nature of students' perceptions of the museum as an educational environment and its contents, which is important for the simultaneous modeling of the school curriculum and museum activities.

\section{References}

Anning A. (2003). Pathways to the graphiacy club: The crossroad of home and preschool. Journal of Early Childhood Literacy, 3(1), 5-35. http://dx.doi.org/10.1177/14687984030031001

Anning A., \& Ring K. (2004). Making sense of childrens drawing. London: Open University Press

Buggle F. (2002). Razvojna psihologija Jeana Piageta. Zagreb: Naklada Slap.

Carini P. (1982). The school lives of seven children: A five year study. Grand Forks, NO: University of North Dakota.

Cohen L., Manion L., \& Morrison K. (2006). Metode istraživanja u obrazovanju. Zagreb: Naklada Slap.

Coles R. (1986). The political life of children. Boston: Atlantic Monthly Press.

Cuero K. K. (2008). Venturing into unknown territory: Using aesthetic representations to understand reading comprehension. International Journal of Education and the Arts, 9(1). Retrieved September 30, 2013, from http://www.ijea.org/v9n1/

De Zan D. (2013). Slika i crtež u psihoterapiji djece i obitelji. Zagreb: Medicinska naklada.

Fassler D. G. (1986). Children's drawings from China and the Soviet Union. Childhood Education, 63(1), 30-38. http://dx.doi.org/10.1080/00094056.1986.10520767

Gamradt J., Staples C., \& Curry J. (1991). Establishing baseline data for a study of transformational processes in schools, Analyzing children's drawings II. Chicago: American Educational Research Association.

Hall E. (2008). “My brain printed it out!’ Drawing, communication, and young children: a discussion. Presented on British Educational Research Association Annual Conference, Heriot-Watt University, Edinburgh, 3-6 September 2008. Retrieved May 15, 2013, from http://www.leeds.ac.uk/educol/documents/174158.pdf

Hawkins B. (2002). Children's drawing, self expression, identity and the imagination. International Journal of Art and Design Education, 21(3), 209-219. http://dx.doi.org/10.1111/1468-5949.00318

Horstman M., Aldiss S., Richardson A., \& Gibson F. (2008). Methodological Issues When Using the Draw and Write Technique with Children Aged 6 to 12 Years. Qualitative Health Research, 18(7), 1001-1011. http://dx.doi.org/10.1177/1049732308318230

Kuhn P. (2003). Thematic Drawing and Focused, Episodic Interview upon the Drawing-A Method in Order to Approach to the Children's Point of View on Movement, Play and Sports at School. Forum: Qualitative Social Research, 4(1). Retrieved September 30, 2013, from http://nbn-resolving.de/urn:nbn:de:0114-fqs030187 
Locke T., \& Riley D. (2009). What happened to educational criticism? Engaging with a paradigm for observation. Educational Action Research, 17(4), 489-504. http://dx.doi.org/10.1080/09650790903309342

Louis L. (2005). What children have in mind: A study of early representational development in paint. Studies in Art Education, 46(4), 339-355.

MacGregor J. (1989). The discovery of the art of the insane. Lawrenceville, NJ: Princeton University Press.

Magolda P., \& Ebben K. (2007). From schools to community learning centers: A program evaluation of a school reform process. Evaluation and program planning, 30(4), 351-363. http://dx.doi.org/10.1016/j.evalprogplan.2007.08.001

Malchiodi C. (1998). Understanding children’s drawings. New York, London: The Guilford Press.

Porter G. (2011). Drawing a circle in the sand: Oral storytelling as a therapeutic intervention with trauma clients. ProQuest Dissertations and Thesis. Retrieved May 15, 2013, from http://search.proquest.com/docview/862344965?accountid=152796

Reeve S., \& Bell P. (2009). Children's self-documentation and understanding of the concepts 'healthy' and 'unhealthy. International Journal of Science Education, 31(14), 1953-1974. http://dx.doi.org/10.1080/09500690802311146

Silver R., \& Ellison J. (1995). Identifying and assessing self-images in drawings by delinquent adolescents. The Arts in Psychotherapy, 22(4), 339-352. http://dx.doi.org/10.1016/0197-4556(95)00038-7

Wilson B., \& Wilson M. (1987). Pictorial composition and narrative structure: Themes and the creation of meaning in the drawings of Egyptian and Japanese children. Visual Arts Research, 13, 10-21.

Winnicott D. (1971). Playing and reality. New York: Basic Books.

Wittmann B. (2010). Drawing cure: Children's drawings as a psychoanalytic instrument. Configurations, 18(3), 251-272. http://dx.doi.org/10.1353/con.2010.0016 